International Journal of Applied Dental Sciences 2021; 7(2): 174-177

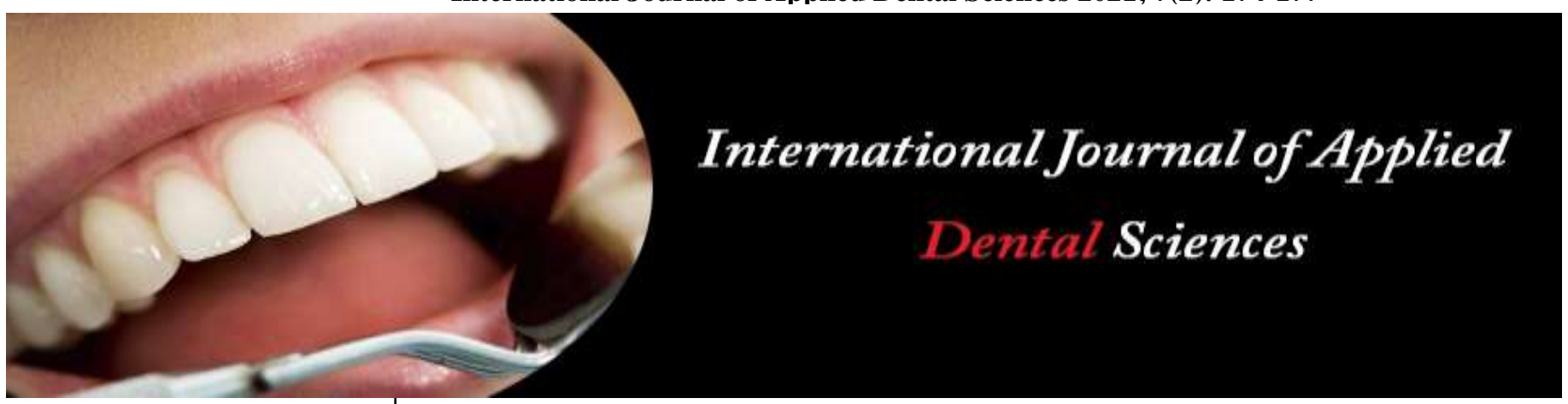

ISSN Print: 2394-7489

ISSN Online: 2394-7497

IJADS 2021; 7(2): 174-177

(C) 2021 IJADS

www.oraljournal.com

Received: 21-01-2021

Accepted: 03-03-2021

Nadia Rasoo

PG Scholar, Department of

Conservative Dentistry and

Endodontics, Yenepoya Dental

College, Manglore, Karnataka, India

Sneha Mariam Lal

PG Scholar, Department of Conservative Dentistry and

Endodontics, Yenepoya Dental

College, Manglore, Karnataka,

India

S Vidhyadhara Shetty

Professor, Department of

Conservative Dentistry and

Endodontics, Yenepoya Dental College, Manglore, Karnataka,

India
Corresponding Author:

Nadia Rasool

PG Scholar, Department of Conservative Dentistry and

Endodontics, Yenepoya Dental College, Manglore, Karnataka, India

\section{Efficacy of pre-operative diclofenac sodium in the control of post-endodontic pain}

\author{
Nadia Rasool, Sneha Mariam Lal and S Vidhyadhara Shetty
}

DOI: https://doi.org/10.22271/oral.2021.v7.i2c.1206

\section{Abstract}

Introduction: The severity as well as the incidence of postoperative pain are associated with specific dental treatments, the highest being root canal therapy. The postoperative pain incidence has been reported to range from $3 \%$ to $58 \%$ after root canal treatment. The aim of the present study was to compare the efficacy of preoperative diclofenac sodium in the control of post-endodontic pain.

Materials and Method: 120 patients were randomly selected and clinical examinations were conducted. The patients were randomly allocated using simple randomization technique into 2 experimental groups: Group 1, diclofenac sodium (VOVERON SR, $100 \mathrm{mg}$-oral) and Group 2, placebo (sucrose tablets). Both medications were administered $30 \mathrm{~min}$ before conventional root canal therapy. Patients were instructed to complete a pain diary; 6,12 , and $24 \mathrm{~h}$ after root canal instrumentation. The method used to measure clinical pain intensity was the visual analogue scale (VAS), which consisted of a $10 \mathrm{~cm}$ line anchored by two extremes, "no pain" and "pain as bad as it could be." Thus, the pain intensity was assigned into four categorical scores: a) None (0); b) Mild (1-3); c) Moderate (4-6); and d) Severe (7-10).

Results: Among the 120 volunteers who completed the study, $63.63 \%$ had mild pain and $36.37 \%$ had severe pain. Post endodontic pain showed a statistically significant difference between group 1 and group 2 at $6 \mathrm{hr}, 12 \mathrm{hr}$ and $24 \mathrm{hr}(P<0.05)$.

Conclusion: Post endodontic pain was substantially reduced by preoperative administration of a single oral dose of diclofenac sodium as compared to the placebo group.

Keywords: Diclofenac sodium, post-endodontic pain, root canal therapy

\section{Introduction}

The severity as well as the incidence of postoperative pain are associated with specific dental treatments, the highest being root canal therapy ${ }^{[1]}$. The postoperative pain incidence has been reported to range from $3 \%$ to $58 \%$ after root canal treatment ${ }^{[2]}$. Pak and White showed that post-obturation pain (POP) prevalence was $40 \%$ at 24 hours, and reduced to $11 \%$ at 1 week $^{[3]}$. The severity of pain was substantially decreased within the first 2 days. In another study, $12 \%$ of patients experienced severe pain within 24 to 48 hours following treatment ${ }^{[4]}$.

There is a strong relationship between pulp status and postoperative pain ${ }^{[5]}$. It is suggested that patients with severe preoperative endodontic pain, vital pulp, symptomatic teeth without periradicular lesions and level of anxiety experience more postoperative pain ${ }^{[6]}$.

The postoperative pain is due to exacerbation of inflammatory response and release of inflammatory mediators which include prostaglandins that activate sensitive nociceptor in periapical tissues. A variety of drugs have been used to manage postoperative pain such as opioids, non-steroidal anti-inflammatory drugs and combinations of drugs ${ }^{[7]}$. Amongst these, the most recommended class of pain relievers in dentistry today are the NSAIDS ${ }^{[8,9]}$. NSAIDS function by inhibiting the cyclooxygenase enzymes and preventing the generation of new prostaglandin molecules; however, they have no effect against existing molecules in circulation ${ }^{[10]}$.

The incidence of postoperative pain has been reported to be greater in single visit root canal treatment than multiple visits. Therefore, the aim of the present study was to evaluate the efficacy of NSAIDS compared with sucrose tablets in reducing postoperative endodontic discomfort in patients. Also, the timing of drug administration was assessed to set a protocol for single visit endodontics. 


\section{Materials and Methods}

The study was conducted in the department of Conservative Dentistry and Endodontics, and institutional ethical clearance was obtained. 120 patients were randomly selected. The examination included palpation and percussion evaluation, thermal tests (cold), periapical radiograph and mobility assessment.

The inclusion criteria for the study were, patients with a vital tooth and irreversible pulpitis but without periapical abscess; and patients with moderate-severe pain. The exclusion criteria included patients who reported any sensitivity or other adverse reaction to NSAIDS, on anti-inflammatory drugs and analgesics, requirement for prophylactic antibiotics, with hypertension, mental disabilities, pregnancy or lactation, systemic diseases, and patients allergic to diclofenac sodium. Using simple randomization technique, the patients were randomly divided into 2 experimental groups: Group 1, diclofenac sodium (VOVERON SR, $100 \mathrm{mg}$-oral) and Groups 2, placebo (sucrose tablets).

The medications (for both the groups) were administered 30 min before root canal therapy. The double-blind design was maintained, a second investigator provided the two agents (diclofenac sodium and sucrose tablets), the operator as well as the patient were not aware of the medication as each tablet was disguised. Treatment was completed in single visit in all cases.

With a 2\% lidocaine solution having 1:100,000 epinephrine, each patient was anesthetized and the access opening was done. The working length was determined by both 15 size Kfile and radiograph, and cleaning and shaping of canals was done using a step-back technique. The canals were enlarged to a $2 \%$ (number 25) and 6\% (number 25) rotary system. Between each file, irrigation was done with $2.5 \%$ sodium hypochlorite and normal saline solution $(0.9 \%$ of $\mathrm{NaCl})$. The canals were dried using paper points post instrumentation followed by obturation.

After root canal instrumentation, the patients were instructed to maintain a pain diary at 6,12 , and $24 \mathrm{~h}$. The visual Numeric scale was used to measure the pain intensity, having $10 \mathrm{~cm}$ line with two extremes, "no pain" and "bad pain". The patients were asked to mark on the line that represented their level of pain. As rescue medicine, another dose of Diclofenac Sodium was prescribed to the patients, if needed. The intensity of pain was divided into four categorical scores: a. None (0); b. Mild (1-3); c. Moderate (4-6); and d. Severe (7$10)$.

The statistical analysis was performed using Fisher's exact test to study the comparisons. A Chi-square test was applied to analyse the status of pain at each level between groups. The program SPSS Version 16 was used for all calculations. The significance levels were set at $5 \%(P<0.05)$.

\section{Results}

Out of the 120 volunteers who completed the study, $63.63 \%$ had mild pain and severe pain was reported by $36.37 \%$. Diclofenac sodium treatment was associated with very low levels of endodontic pain. At $24 \mathrm{hrs}$ of endodontic treatment, in both the groups, few patients reported with pain. Postendodontic pain showed a statistically significant difference between group 1 and group 2 at $6 \mathrm{hr}, 12 \mathrm{hr}$ and $24 \mathrm{hr}(P<0.05)$.

Table 1: Pain intensity in different groups at $6 \mathrm{hrs}, 12 \mathrm{hrs}$ and $24 \mathrm{hrs}$

\begin{tabular}{|c|c|c|c|}
\hline \multirow{3}{*}{ Time intervals } & Clinical pain intensity & Group 1 (Diclofenac sodium) & Group 2 (Placebo) \\
\cline { 2 - 4 } & & No. of patients & No. of patients \\
\hline \multirow{4}{*}{ At $6 \mathrm{hrs}$} & No pain & 60 & 16 \\
& Mild & 0 & 28 \\
\cline { 2 - 4 } & Moderate & 0 & 14 \\
\cline { 2 - 4 } & Severe & 0 & 2 \\
\hline \multirow{4}{*}{ At $12 \mathrm{hrs}$} & No pain & 38 & 6 \\
\cline { 2 - 4 } & Mild & 18 & 30 \\
\cline { 2 - 4 } & Moderate & 4 & 22 \\
\hline \multirow{3}{*}{ At $24 \mathrm{hrs}$} & Severe & 0 & 2 \\
\cline { 2 - 4 } & No pain & 46 & 26 \\
\cline { 2 - 4 } & Mild & 14 & \\
\cline { 2 - 4 } & Moderate & 0 & 34 \\
\hline
\end{tabular}




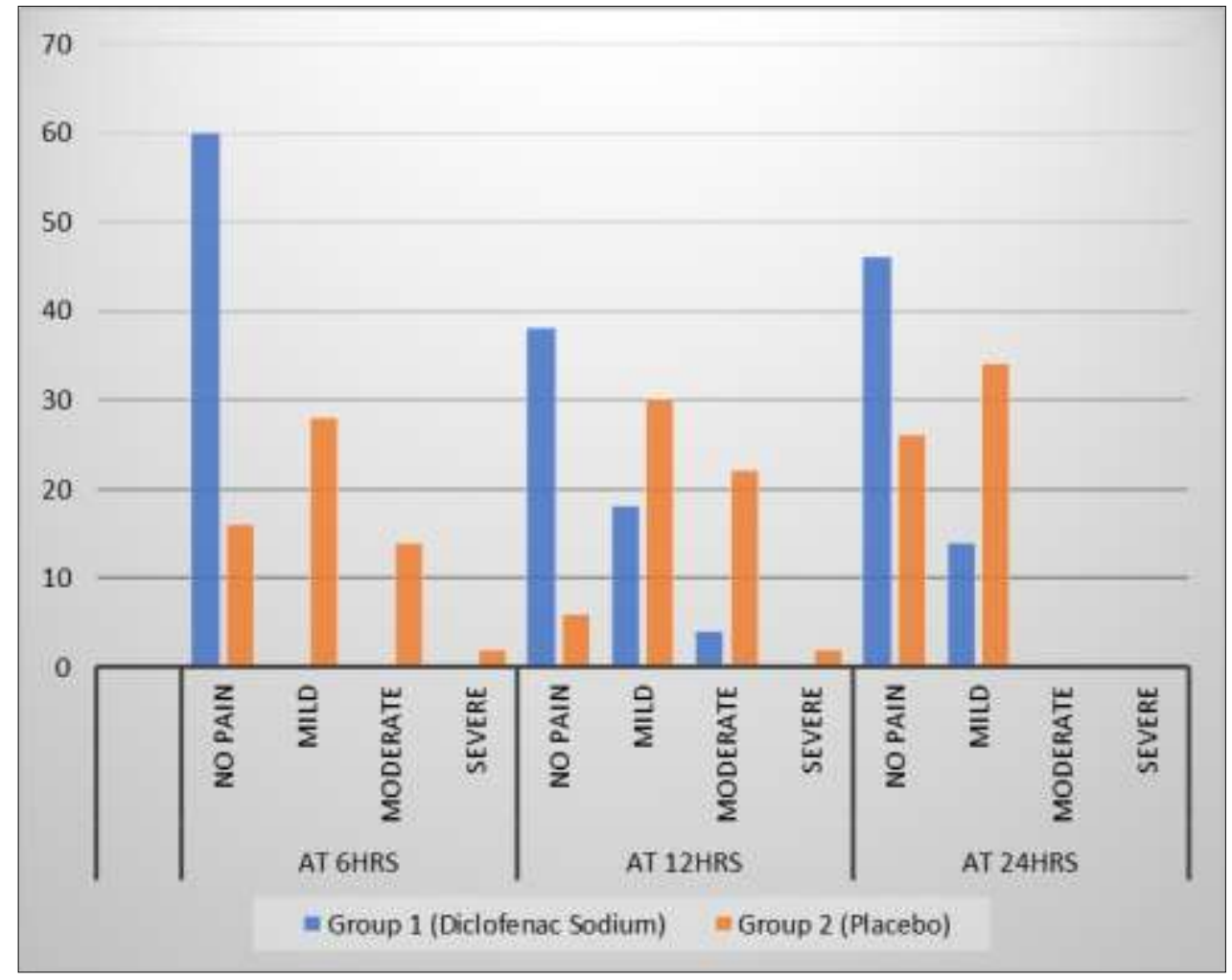

Fig 1: Pain intensity in different groups at $6 \mathrm{hrs}, 12 \mathrm{hrs}$ and $24 \mathrm{hr}$

\section{Discussion}

Postoperative pain is an unpleasant experience after root canal therapy. Such pain arises as a consequence of periradicular damage and due to inflammatory mediators ${ }^{[11,12]}$. Based on data suggesting the potential involvement of antiinflammatory process in the pathophysiology of endodontic pain, non-narcotic analgesics including NSAIDs and/or paracetamol have been used for treatment of post-endodontic pain ${ }^{[13]}$.

In the present study, the intensity of post-endodontic pain was evaluated by $100-\mathrm{mm}$ visual Numeric scale in correspondence to the studies done by various authors ${ }^{[14-16]}$. The rescue medication (Diclofenac sodium) which was prescribed to both the groups was not taken by any patient. It was observed that sucrose tablets did not result in significant reduction of pain in comparison with diclofenac sodium at the 6-h, 12-h and 24-h time point (Table 1).

Oral administration of drugs was preferred because of its convenience and effectiveness, since the use of intravenous or intramuscular injection may lead to fear and discomfort in some patients ${ }^{[17-19]} .30 \mathrm{~min}$ before the root canal therapy, diclofenac sodium was administered. The primary mechanism responsible for its analgesic, anti-inflammatory, and antipyretic actions is inhibition of cyclooxygenase, which leads to inhibition of prostaglandin synthesis. Moreover, the high potency of diclofenac may be ascribed to the inhibition of lipoxygenase pathways, thereby reducing the formation of leukotrienes. It may also inhibit phospholipase A2. Preoperative, single, oral dose of NSAIDS can modulate the release of inflammatory mediators and reduce the side effects compared with repeated doses during the postoperative period ${ }^{[20]}$. Pre-treatment analgesia before root canal treatment may decrease the establishment of central sensitization whereby spinal neurons increase their responsiveness to peripheral nociceptive input ${ }^{16}$ which could amplify postoperative pain [21]. Pre-operative administration, as well, would be of particular significance with glucocorticoids which may require time for their effects to be mediated ${ }^{[22]}$.

Metri et al. ${ }^{[23]}$ in 2017 by using a visual numeric scale assessed postoperative pain at 6,12 , and $24 \mathrm{~h}$ after preoperative administration of diclofenac sodium. They suggested that the effectiveness of preoperative administration of diclofenac sodium in the reduction of post-endodontic pain may help patients with a low pain threshold in pain prevention [23]. However, in a few endodontic and oral surgery procedures, the optimal moment for oral administration of NSAIDS was evaluated $[18,24,25]$. This double-blind randomized trial allowed sufficient comparison between both NSAID and Sucrose tablet groups.

\section{Conclusion}

Post-endodontic pain was significantly less in patients with preoperative administration of diclofenac sodium (single oral dose) as compared to the sucrose group. It is possible that in patients with a low pain threshold, these results might help to prevent post-endodontic pain. Further studies with multiple variables are required to substantiate the results of the present study to achieve pain free dentistry.

\section{References}

1. Levin L, Amit A, Ashkenazi M. Post-operative pain and use of analgesic agents following various dental procedures. Am J Dent 2006;19:245-7.

2. Harrison JW, Baumgartner IC, Zielke DR. Analysis of interappointment pain associated with the combined use of endodontic irrigants and medicaments. J Endod 1981;7:272-6.

3. Pak JG, White SN. Pain prevalence and severity before, during, and after root canal treatment: a systematic review. J Endod 2011;37:429-38.

4. $\mathrm{Ng} \mathrm{YL,} \mathrm{Glennon} \mathrm{JP,} \mathrm{Setchell} \mathrm{DJ,} \mathrm{Gulabivala} \mathrm{K.}$ Prevalence of and factors affecting postobturation pain in patients undergoing root canal treatment. Int Endod $\mathbf{J}$ 2004;37(6):381-91. 
5. Tsesis I, Faivishevsky V, Fuss Z, Zukerman O. Flare-ups after endodontic treatment: a meta-analysis of literature. J Endod 2008;34(11):77-81.

6. Menke ER, Jackson CR, Bagby MD, Tracy TS. The effectiveness of prophylactic etodolac on postendodontic pain. J Endod 2000;26:712-5.

7. Whitten BH, Gardiner DL, Jeansonne BG, Lemon RR. Current trends in endodontic treatment: report of a national survey. J Am Dent Assoc 1996;127:1333-41.

8. Yingling NM, Byrne BE, Hartwell GR. Antibiotic use by members of the American Association of Endodontists in the year 2000: report of a national survey. J Endod 2002;28:396-404.

9. Mulrow CD. Rationale for systematic reviews. BMJ 1994;309(6954):597-9.

10. Rainsford KD. Anti-inflammatory drugs in the $21 \mathrm{st}$ century. Subcell Biochem 2007;42:3-27.

11. Hargreaves KM, Berman LH. Cohen's pathways of the pulp expert consult: Elsevier Health Sciences 2015.

12. Glenny AM, Altman DG, Song F, Sakarovitch C, Deeks JJ, D'Amico R et al. Indirect comparisons of competing interventions. Health Technol Assess 2005;9(26):1-134.

13. Ong K, Seymour R. Maximizing the safety of nonsteroidal anti-inflammatory drug use for postoperative dental pain: an evidence-based approach. Anesthesia Progress 2003;50(2):62.

14. Gopikrishna V, Parameswaran A. Effectiveness of prophylactic use of rofecoxib in comparison with ibuprofen on post endodontic pain. $\mathrm{J}$ Endod 2003;29(1):62-4.

15. Attar S, Bowles WR, Baisden MK, Hodges JS, McClanahan SB. Evaluation of pre-treatment analgesia and endodontic treatment for postoperative endodontic pain. J Endod 2008;34(6):652-5.

16. Arslan H, Topcuoglu HS, Aladag H. Effectiveness of tenoxicam and ibuprofen for pain prevention following endodontic therapy in comparison to placebo: a randomized double-blind clinical trial. J Oral Sci 2011;53(2):157-61.

17. Marshall JG. Consideration of steroids for endodontic pain. Endod Topics 2002;3:41-51.

18. Pilatti GL, André dos Santos F, Bianchi A, Cavassim R, Tozetto CW. The use of celecoxib and dexamethasone for the prevention and control of postoperative pain after periodontal surgery. J Periodontol 2006;77:1809-14.

19. Glassman G, Krasner P, Morse DR, Rankow H, Lang J, Furst ML. A prospective randomized double-blind trial on efficacy of dexamethasone for endodontic interappointment pain in teeth with asymptomatic inflamed pulps. Oral Surg Oral Med Oral Pathol 1989;67:96-100.

20. Pochapski MT, Santos FA, de Andrade ED, Sydney GB. Effect of pre-treatment dexamethasone on post endodontic pain. Oral Surg Oral Med Oral Pathol Oral Radiol Endod 2009;108:790-5.

21. Kissin I. Preemptive analgesia. Anesthesiol 2000;93(4):1138-43.

22. Marshall JG. Consideration of steroids for endodontic pain. Endod Topics 2002;3:41-51.

23. Metri M, Hegde S, Bhandi S. Effect of pre-treatment diclofenac sodium on postendodontic pain: A randomised controlled trial. J Conserv Dent 2016;19:7-10.

24. Schmelzeisen R, Frölich JC. Prevention of postoperative swelling and pain by dexamethasone after operative removal of impacted third molar teeth. Eur J Clin Pharmacol 1993;44(3):275-7.
25. Schultze-Mosgau S, Schmelzeisen R, Frölich JC, Schmele H. Use of ibuprofen and methylprednisolone for the prevention of pain and swelling after removal of impacted third molars. J Oral Maxillofac Surg 1995;53:27. 